\title{
Analysis of the clinical effects of using naloxone hydrochloride in emergency treatments of acute alcoholism.
}

\author{
Wei Gou ${ }^{1,2 * \#}$, Ling Peng ${ }^{3 \#}$, Qinghua Yang ${ }^{4}$, Lewei Cao ${ }^{4}$ \\ ${ }^{1}$ Department of Neurology, the Seventh People's Hospital of Chengdu, Chengdu, Sichuan, PR China \\ ${ }^{2}$ Department of Geriatrics, the Seventh People's Hospital of Chengdu, Chengdu, Sichuan, PR China \\ 3Department of Neurology, the Institutional Hospital of Chengdu Military Command, Chengdu, Sichuan, PR China \\ 4Department of Endocrinology, the Seventh People's Hospital of Chengdu, Chengdu, Sichuan, PR China \\ \#These authors contributed equally to this paper
}

\begin{abstract}
Objective: This study aimed to analyse the clinical effects of using naloxone hydrochloride in emergency treatments of acute alcoholism.

Methods: A total of 146 patients admitted between August 2015 and August 2017 in the hospital where the author works were divided into control $(n=73)$ and test $(n=73)$ groups using the odd-even method. Routine and naloxene hydrochloride treatments were administered to the control and test groups, respectively. The clinical effects on the two groups were then compared.

Results: The overall response rate of the test group was significantly higher $(P<0.05)$ than that of the control group. The test group significantly outperformed the control group in terms of onset, symptom remission, and symptom disappearance times. The two groups were also compared in terms of limbmovement recovery time, the time when GCS rating reaches eight points, and the duration of hospitalization. Similarly, the test group again showed a significantly higher $(P<0.05)$ performance than the control group. Furthermore, the test and control groups were compared in terms of negative response rate, wherein no significant difference $(P<0.05)$ was observed.

Conclusions: The use of naloxone hydrochloride in the emergency treatment of acute alcoholism was reliable, effective, and safe. The compound can significantly alleviate the patients' clinical symptoms and shorten the recovery time. Therefore, further clinical application of naloxone hydrochloride should be promoted.
\end{abstract}

Keywords: Naloxone hydrochloride, Acute alcoholism, Emergency treatment.

Accepted on October 28, 2017

\section{Introduction}

Acute alcoholism is one of the commonly seen disorders handled by the Clinical Department [1]. If one takes alcohol beyond the upper limit in a short period of time, the Central Nervous System (CNS) gets excited first and then inhibits the alcohol intake. The sudden change can cause serious damage of the CNS, the liver, and other human organs [2,3]. Immediate treatments can help the patient to get through smoothly the critical period of the disorder and reduce the occurrence of complications. If not treated immediately and effectively, acute alcoholism can directly pose a threat to a patient's life. Naloxone hydrochloride is usually applied for clinical treatment of acute alcoholism, and has achieved significant treatment effects [4]. A total of 146 patients were admitted between August 2015 and August 2017 in the hospital where the author works in for a comparative analysis with the patients which were then divided into control and test groups.

\section{Materials and Methods}

\section{General data}

In this study, a total of 146 patients were admitted between August 2015 and August 2017 in the hospital where the author works in. The odd-even method was employed to divide the patients into control $(n=73)$ and test $(n=73)$ groups. The control group was consisted of 60 male and 13 female patients with an age range of 20-56 y old and an average age of $38.5 \pm 3.2 \mathrm{y}$ old. The drainage volume was in the scope of 260 and $890 \mathrm{ml}$, with an average of $650.3 \pm 45.8 \mathrm{ml}$. The treatment was taken from $20 \mathrm{~min}$ to $3 \mathrm{~h}$ of taking alcohol, with an average of $1.5 \pm$ $0.6 \mathrm{~h}$. Of all the patients in the control group, 10 cases were 
taken into coma period, 28 cases in the ataxia period, and 35 cases in the excitement period. On the other hand, the test group was consisted of 61 male and 12 female patients with an age range of 21-57 y old, an average age of $37.6 \pm 3.4 \mathrm{y}$ old. The drainage volume was in the scope of 262 and $895 \mathrm{ml}$, with an average of $654.5 \pm 45.5 \mathrm{ml}$. The treatment was taken from $22 \mathrm{~min}$ to $2 \mathrm{~h}$ of taking alcohol, with an average of $1.3 \pm 0.5 \mathrm{~h}$. Of all the patients in the test group, 12 cases were taken into the coma period, 27 in the ataxia period, and 34 in the excitation period. In general, difference of the two groups was not statistically significant $(\mathrm{P}>0.05)$. Thus, a comparative analysis between the two groups was feasible.

\section{Methods}

The routine treatment was administered to the patients of the control group through the emetic method and the gastric lavage. The patients have immediately inhaled oxygen to guarantee the smoothness of the respiratory tract. Intravenous dripping of glucose saline, (concentration: 5\%-10\%) was adopted to fully supplement blood volume. vitamins, including vitamin B6 and vitamin $\mathrm{C}$, were used to rectify imbalance of water and electrolytes, and maintain acid-base equilibrium. A $20 \mathrm{mg}$ furosemide was given through intravenous furosemide to accelerate the discharge of alcohol. Patients, who are spitting blood or having hyperemesis, have received intramuscular injection of $10 \mathrm{mg}$ of metoclopramide to stop the bleeding and protect the gastric mucosa. The test group received not only the routine treatment, but also the naloxone hydrochloride treatment. Patients in the excitement, ataxia, and coma periods of acute alcoholism took a dose of 0.4-0.8 mg, 0.8-1.2 mg. and 1.2-1.6 $\mathrm{mg}$ of naloxone hydrochloride, respectively. During the medication process, changes in patients' vital signs, mental status, and pupil dilation were strictly observed and noted once every 15-30 min. After the medication process, the patients' mental status was still observed. If the patients still fail to recover from the coma status within $30 \mathrm{~min}$ to $1 \mathrm{~h}$, the above dosage of naloxone hydrochloride can be given to the patients repeatedly until the patients have come to their senses.

\section{Observation indices}

The difference in onset time, symptom remission time, and symptom disappearance time between the two groups was statistically analysed.

Negative responses, including low blood pressure, arrhythmia, cephalophyma and respiratory depression, on the patients in the two groups, during the treatment process were evaluated.

The time it takes for the GCS rating to reach eight points was also observed, having three criteria to evaluate the GCS rating, including language response, limb movement, and eye-opening reaction. The total points is 15 points indicating that the higher the total points obtained, the more serious the degree of coma. Meanwhile, the time it took for the patient to have their movement functions recovered and to be discharged from the hospital were also evaluated.

\section{Treatment effect evaluation criteria}

Criteria of excellence: All clinical symptoms have disappeared. Patients have recovered their senses, movements, and language functions, capable of speaking fluently and acting harmoniously.

Criteria of improvement: The clinical symptoms significantly had alleviated, and patients had recovered their senses, movements, and language functions to a larger extent. Patients have spoken a little, are behaving naturally, and have improved their degree of their movement coordination.

Criteria of failure: The treatment effects have failed to reach the criteria of excellence or improvement, or patients' illness is significantly aggravated as compared with their illness before treatment.

The overall response rate of patients can be calculated by dividing the total cases with treatment failure cases subtracted by the total cases. Overall response rate $=(($ Total casestreatment failure cases)/total cases) $\times 100 \%$.

\section{Statistical analysis}

All data obtained were entered in SPSS21.0 software for statistical processing and analysis. The correlation rating and time is represented by $(\overline{\mathrm{x}} \pm \mathrm{s})$. T-test and $\chi^{2}$-test were calculated for intergroup comparisons. The overall response rate and the negative response rate are represented in percentage. The statistical significance was evaluated with a level of significance 0.05 , with $\mathrm{P}<0.05$ meaning significant difference.

\section{Results}

\section{Intergroup comparison of the treatment overall response rate}

The overall response rate of the treatments for the control and test groups was $83.6 \%$ and $97.3 \%$, respectively. Intergroup comparison suggested that the overall significant rate of the control group was significantly lower $(\mathrm{P}<0.05)$ than that of the test group. Data are shown in Table 1.

Table 1. Comparison of the overall response rate (n (\%)) of the control and test groups.

\begin{tabular}{lllll}
\hline Group & Excellence & Improvement & Failure & $\begin{array}{l}\text { Overall } \\
\text { response } \\
\text { rate }\end{array}$ \\
\hline $\begin{array}{l}\text { Control group } \\
(n=73)\end{array}$ & $24(50.7)$ & $24.9)$ & $12(16.4)$ & $61(83.6)$ \\
\hline $\begin{array}{l}\text { Test group } 51(69.9) \\
(n=73)\end{array}$ & $20(27.4)$ & $2(2.7)$ & $71(97.3)$ \\
\hline$X^{2}$-value & & & 11.9455 \\
\hline P-value & & 0.0005 \\
\hline
\end{tabular}




\section{Comparison of the onset time, symptom remission time and symptom disappearance time}

The onset time, symptom remission time, and symptom disappearance time of the control group were significantly longer $(\mathrm{P}<0.05)$ than those of the test group. The data are presented in Table 2.

Table 2. Comparisons of the onset time, symptom remission and symptom disappearance time $(\bar{x} \pm s$, in $\mathrm{min})$ of the control and test groups.

\begin{tabular}{|c|c|c|c|}
\hline Group & Onset time & $\begin{array}{l}\text { Symptom } \\
\text { remission time }\end{array}$ & $\begin{array}{l}\text { Symptom } \\
\text { disappearance } \\
\text { time }\end{array}$ \\
\hline $\begin{array}{l}\text { Control } \\
(n=73)\end{array}$ & $80.3 \pm 11.4$ & $160.5 \pm 25.6$ & $364.2 \pm 58.5$ \\
\hline Test group $(n=73)$ & $13.3 \pm 1.5$ & $30.7 \pm 2.6$ & $126.6 \pm 40.4$ \\
\hline t-value & 378.9137 & 43.0990 & 28.5543 \\
\hline P-value & 0.0000 & 0.0000 & 0.0000 \\
\hline
\end{tabular}

Comparison of the time for GCS to reach eight points, for recovery of limb movement and for discharge from the hospital

The time taken by the test group for GCS rating to reach eight points, for recovery of limb movement and for discharge from the hospital were significantly shorter than those of the control group. The intergroup difference was significant and had statistical significance $(\mathrm{P}<0.05)$. The data are shown in Table 3.

Table 3. Comparison of the time taken by the test group and the control group for GCS to reach eight points, for recovery of limb movement and for discharge from the hospital $(\bar{x} \pm s)$.

\begin{tabular}{|c|c|c|c|}
\hline Group & $\begin{array}{l}\text { Time taken by GCS } \\
\text { rating to reach eight } \\
\text { points (min) }\end{array}$ & Limb & $\begin{array}{l}\text { Discharge time } \\
\text { (d) }\end{array}$ \\
\hline Control $(n=73)$ & $94.8 \pm 25.7$ & $165.4 \pm 26.3$ & $2.7 \pm 0.7$ \\
\hline Test $(n=73)$ & $75.6 \pm 30.5$ & $43.3 \pm 12.7$ & $1.6 \pm 0.5$ \\
\hline t-value & 4.113 & 35.7196 & 10.9254 \\
\hline$P$-value & 0.0001 & 0 & 0 \\
\hline
\end{tabular}

\section{Comparison of the negative response rate of the control group and the test group}

The negative response rate of the test and control groups was also compared, showing neither intergroup significant difference nor statistical significance $(\mathrm{P}>0.05)$. The data are shown in Table 4

Table 4. Comparison of the negative response rate of the test group and the control group $(n(\%))$.

\begin{tabular}{|c|c|c|c|c|c|}
\hline Group & Arrhythmia & Low blood pressure & Cephalophyma & $\begin{array}{l}\text { Aggravation of respiratory } \\
\text { inhibition }\end{array}$ & Negative response \\
\hline Control $(n=73)$ & $2(2.7)$ & $1(1.4)$ & $1(1.4)$ & $0(0.0)$ & $4(5.4)$ \\
\hline Test $(n=73)$ & $1(1.4)$ & $1(1.4)$ & $0(0.0)$ & $0(0.0)$ & $2(2.7)$ \\
\hline$x^{2}$-value & & & & & 0.6952 \\
\hline P-value & & & & & 0.4043 \\
\hline
\end{tabular}

\section{Discussions}

Alcoholism is a common clinical symptom. The death rate by alcoholism poses a serious threat to the physical and mental health of patients. After drinking, alcohol enters the blood via the blood capillaries of the stomach and small intestines in a short period of time [5]. The alcohol concentration will reach its peak value within 30 45 min, and then be on a downward trend. Once the $\mathrm{BAC}$ is $\geq 1,000 \mathrm{mg} / \mathrm{L}$, alcoholism happens. Being fat-soluble, alcohol can quickly penetrate through the neural cell membranes of the brain to influence the corresponding enzyme of the cell membranes [6]. The functions of the cells will also be influenced. After a short period of time, alcohol will penetrate the blood brain barrier, simultaneously, due to the strong stress state of the organism, the Hypothalamic Release Factor (HRF) can stimulate continuous release of endogenous opioids via the hypophysis inferior lobe to impact the endogenous opioid receptor, which can further inhibit the function of the CNS [7]. The HRF will then gradually flow downwards to impact all the brain functions via the limbic system, cerebella and, net-like structures. With the continuous increase of the alcohol content, the CNS function is continuously inhibited [8]. An extremely high content of alcohol can curb brain functions, finally causing failure of the circulatory and respiratory systems.

Naloxone hydrochloride is an opioid antagonist and a derivative of oxymorphone. Although being internally inactive, naloxone hydrochloride shows a competitive antagonism against various opioid receptors, but a high affinity towards $\mu$ receptor. Naloxone hydrochloride has specifically the following functions [9,10]: (1) the antagonism of naloxone hydrochloride, after administration, shows its effects quickly. It can reverse the influence of the opium agonist, and has favorable analgesia effect; (2) naloxone hydrochloride can directly promote conversion and decomposition of alcohol, and quickly discharge alcohol from the body; (3) naloxone hydrochloride is also antagonistic to the irrelevant recovery 
effect of the opioid receptor. It can quickly reverse the respiratory inhibition caused by opioid analgesics. After a highly excitation state, the cardiovascular functions will be in a hyper-functioning state; (4) the anti-shock function of naloxone hydrochloride is favorable. It will neither form morphine-like materials, nor give rise to withdrawal symptom and respiratory inhibition; and (5) through intravenous administration, naloxone hydrochloride can quickly reverse the treatment effect of opioids to significantly reduce the $\beta$ endorphin levels of the patients. In this way, the central neural inhibition can be alleviated to improve neural cell metabolism, improve brain functions, restrain generation of free radicals, and significantly dampen the peroxidation of lipids.

\section{Conclusion}

According to findings of this paper, the onset time, symptom remission time, symptom disappearance time, time for GCS rating to reach eight points, time for recovery of limb functions, and time for discharge from the hospital of the test group were significantly lower than those of the control group. The former outperformed the latter in terms of the overall response rate significantly $(\mathrm{P}<0.05)$. In terms of the negative response rate, the two groups showed no significant difference $(\mathrm{P}>0.05)$. Therefore, the emergency application of naloxone hydrochloride to treat acute alcoholism is reliable and safe. Considering the significant improvement of patients' clinical symptoms and shortening of the rehabilitation time, naloxone hydrochloride can be further promoted clinically.

\section{References}

1. Doe-Simkins M, Walley AY, Epstein A, Moyer P. Saved by the nose: bystander-administered intranasal naloxone hydrochloride for opioid overdose. Am J Public Health 2009; 99: 788-791.

2. Jiang J, Zhao J, Yuan Y, Di S. Risk factors associated with acute exacerbation of chronic obstructive pulmonary disease: a retrospective analysis in 4624 patients. Biomed Res India 2017; 28: 3855-3859.

3. Kistner C, Ensom MHH, Decarie D, Lauder G, Carr RR. Compatibility and stability of morphine sulphate and naloxone hydrochloride in $0.9 \%$ sodium chloride for injection. Can J Hosp Pharm 2013; 66: 163-170.

4. Zou J, Zhou L, Zhou X, Wu X, Luo L, Luo Y, Tian J. The analgesic effect, acute toxicity, and influence on central nervous system of the new formula ketoprofen injection prepared by sodium acetate as hydrotropic agent. Lat Am J Pharm 2017; 36: 1361-1370.

5. Ray DAA, Tai YMA. Increasing doses of naloxone hydrochloride by infusion to treat pain due to the thalamic syndrom. Br Med J (Clin Res Ed) 1988; 296: 969-970.

6. Mahdi TN, Gholamhassan V, Hossein AE, Vida H. Acute and chronic effects of opiates and dopamine on yawning, penile erection and genital grooming behaviors in male Wistar rats. Biomed Res India 2017; 28: 6931-6936.

7. Kissler JL, Sirohi S, Reis DJ, Jansen HT, Quock RM, Smith DG, Walker BM. The one-two punch of alcoholism: role of central amygdala dynorphins/kappa-opioid receptors. Biol Psychiatry 2014; 75: 774-782.

8. Maluf DF, Farago PV, Barreira SMW, Pedroso CF, Pontarolo R. Validation of an analytical method for determination of sibutramine hydrochloride monohydrate in capsules by Uv-Vis spectrophotometry. Lat Am J Pharm 2007; 26: 909-912.

9. Heilig M, Egli M, Crabbe JC, Becker HC. Acute withdrawal, protracted abstinence and negative affect in alcoholism: Are they linked? Addict Biol 2010; 15: 169-184.

10.Zorrilla EP, Heilig M, Wit H, Shaham Y. Behavioral, biological, and chemical perspectives on targeting CRF1receptor antagonists to treat alcoholism. Drug Alcohol Depend 2013; 128: 175-186.

\section{*Correspondence to}

Wei Gou

Department of Neurology

The Seventh People's Hospital of Chengdu

PR China 